20 minutes to half an hour to the action of liquid air. They were then at once introduced into healthy mice beneath the skin, the presumption being that in these circumstances the tumour cells would be destroyed by the action of the liquid air, and consequently that they would multiply no further. However, among the inoculations made with the frozen material it was found that in some cases new tumours were produced. Further, in a number of mice wherein tumours of the same strain were already growing similar inoculations were made in a remote part of the body in some of these also the same positive result was obtained. From these observations it is rendered clear that exposure to liquid air at a temperature of about $-195^{\circ}$ does not necessarily destroy the potentiality of the substance of a mouse tumour to produce fresh tumours of the same kind in mice into which such frozen tumour substance has been grafted.

These facts in themselves are somewhat surprising, and they immediately raise a number of questions which it will be desirable to have elucidated in the interests of research concerning the nature of cancer. In the first place, it is rendered clear that exposure to liquid air for a certain period of time does not destroy the principle apon which the vitality of mouse cancer depends. If, as may be the case, the cells composing the mass of the tumour, and constituting the grafts, are killed by exposure to liquid air, then the development of mouse cancer after such exposure indicates not merely that the growth of similar tumours is independent of the integrity of the "cancer cells," but also that the new tissues are not necessarily formed from the implanted cells at all, and may arise from the cells of the new host in response to some stimulus introduced along with the frozen material, and quite independent of the integrity of the socalled "cancer cells."

This matter is at present engaging our attention, but the fact that the capacity for originating new growths is not necessarily destroyed in the substance of tumours after exposure to liquid air, certainly suggests that the production of new tumours in the hosts into which the frozen cancer tissue has been introduced may possibly not be dependent upon the introduction of the "cancer cells" at all, but upon the action of a virus which is independent of these cells, and retains its activity after being subjected to the temperature of liquid air. It is well known that a number of bacteria are not killed by this temperature. The fact that cancer can be originated in mice by implantation of portions of frozen tumours may indicate that there exists some such cause as an organised irritant or paracite acting as an agent in the production of cancer On the other hand, however, it is not yet certain that the cells from the tumour introduced into a new individual are killed by half an hour's exposure to the temperature of liguid air, particularly as the seeds of some plants and trypanosomes are said to survive this temperature.

\section{NOTE UPON THE EFFECT OF LIQUID AIR UPON THE GRAFTABLE CANCER OF MICE.}

BY J. E SALVIN-MOORE, A.R.C.S., F.L S., F.Z S., PROFESSOR OF EXPERIMENTAL AND PATHOLOGICAL CYTOLOGY AND DIRECTOR OF THE CANCER RESEARCH LABORATORIES, UNIVERSITY OF IIVERPOOL;

$A N D$

J. O. WAKELIN BARRATT, D.So., M.D. LOND., F.R C.S. ENG.

Is the present communication we wish to record some observations made upon the graftable tumours of mice. The tumours under observation were obtained for the Liverpcol Cancer Research Laboratories, through the kindness of Professor Bang of Copenhagen, and were received originally from Professor Jensen. For purposes of certain experiments not yet completed fragments of the tumour in question were placed in liquid air for from 20 minutes to half an hour and after thawing were placed under the skin of fresh mice in the ordinary way. It was presumed that by exposure to the temperature of liquid air the tumour cells would be immediately killed. However, in a number of such grafts after a period of from ten to 20 days fresh tumours appeared at the site of the inoculations.
These observations appear to be of interest in themselves ; but more especially so because they lead up to a number of important questions. It seems to be probable from what has been observed in relation to healthy skin that exposure to the temperature in liquid air rapidly kills the cells composing it. It may, of course, be that cancer cells differ in their capacity to resist such a temperature, but at the same time since some bacteria and other organisms are known not to be killed by the temperature in question it is clearly suggested that there may be an organism in or among the cancer cells able to withstand the treatment to which they have been subjected and afterwards consequently capable of setting up the formation of a tumour derived from the tissues of a new host. These are, however, matters which are engaging our attention and at present it is undesirable to say more concerning them.

\section{TREATMENT OF GRAVES'S DISEASE WITH THE MILK OF THYROIDLESS} GOATS.

By WALTER EDMUNDS, M.A., M.C. Cantab., F.R.C.S. ENG.,

SURGEON TO THE PRINCE OF WALES'S HOSPITAL, TOTTENHAM.

SINCE the discovery of the nature of myxoedema it has been thought that the symptoms of Graves's disease are due to an excessive secretion from the enlarged thyroid gland Further, it has been thought that a remedy might be found in the serum or milk of thyroidless animals, the idea being that to counteract the thyroid secretion the normal body secretes an antithyroidin, and that in thyroidless animals this antithyroidin would be in excess and available to act as an antidote to the excess of thyroid secretion in Graves's disease.

There are, however, some difficulties in the way of this theory. The severity of the symptoms of Graves's disease is by no means always in proportion to the size of the goitre, nor is this always one of the first symptoms ; indeed, from the history of the cases it would seem that they often start from some mental strain. Another difficulty arises from the fact that myxœedema and Graves's disease sometimes coexist. Babinski mentions two such cases and Dr. Samuel West has recently recorded a very clear case occurring under his care at St. Bartholomew's Hospital.

A third difficulty arises from the symptoms produced by the excision of the thyroid varying in different animals. In dogs and cats the operation produces severe nervous symptoms, tremors, paralysis, and convulsions, quickly followed by death. In goats, on the other hand, as a rule no ill effects follow. I have recently performed the operation on ten goats. One of them was young and not fully grown; the effect of the operation was that it ceased to grow and became in fact a cretin. The other nine goats were fully grown and in seven of them the operation produced no effect; in the other two there came on after some montbs a swelling of the face, due no doubt to myxodema; this was treated with thyroid tabloids and disappeared but both animals died. A small percentage of the doga submitted to complete thyroidectomy escape the acute symptoms; they then remain well; they do not later develop myxœdema nor does this occur in those dogs in which nearly the whole of the thyroid gland is removed and one or more parathyroids are left. Thus dogs do not have myzodema and goats do not have the acute nervous symptoms which occur in dogs and which are attributed by Gley and others to the removal of the parathyroid glands. Monkeys, however, which are nearer to man than either dogs or goats, may have aparathyroidea or myxœedema or both. As a rule, it seems that monkeys when submitted to thyroidectomy die from the nerve symptoms; those, however, which survive or escape this may have, and some do have, myxœ lema.

Thus, even if it is admitted that the symptoms of Graves's disease are due to the thyroid secretion, the question may not be merely one of too much or too little, but we may have to distinguish between the secretion from the thyroid proper and that from the parathyroids.

A fourth, and last, objection to the theory is that it leaves out of account the possibility of any action of the central nervous system on the secretion of the gland. Fixner, and later myself, have shown reason for thinkirg that there is 